\title{
Reply to Dr H Gardner
}

\author{
Matthieu Vinchon
}

Received: 4 July 2010 / Accepted: 7 July 2010 / Published online: 31 July 2010

(C) Springer-Verlag 2010

\section{Dear Editor,}

I appreciate the interest manifested by Dr. Gardner for our study. However, I would like to urge caution against rushing to the conclusion that all subdurals in infants with large subarachnoid spaces are spontaneous. I do not think that "the entire abuse literature needs revision", however, criticism should be exercised when reading past articles, especially regarding the basis on which cases of subdural hematomas were declared accidental or not.

Our previous paper [1], based on abusers' confessions, confirmed that violent shaking is the most common cause of subdural in infants. In our total series (unpublished data), the vast majority of subdurals in infants without evidence of trauma were diagnosed as child abuse, very often confirmed by confession and/or judicial sanction.

What we wanted to stress in the present paper is that not all subdurals are traumatic, and that clinicians should exercise much caution when evaluating an infant with subdural hematoma for possible child abuse. This evaluation must include complete physical examination by a pediatrician, early ophthalmological examination by an ophthalmologist, coagulation study, skeletal survey, and reconstruction of the head circumference curve. In the presence of positive features (bruises, severe retinal hemorrhage, or bone fractures), the diagnosis of abuse (or at least the need to refer the case to the judiciary) is clear. In the absence of all of these features, the question is still open, and many of these cases were found to be abusive trauma [2].

Since negative features are not sufficient to assert the absence of trauma, we tried to identify positive features in favor of spontaneous bleeding, like arachnoidomegaly, preexisting macrocrania or dehydration. This effort was made in a strictly medical perspective; we leave it to the competent authorities to ponder the legal implications of these findings.

\section{References}

1. Vinchon M, deFoort-Dhellemmes S, Desurmont M (2010) Delestret I confessed abuse versus witnessed accidents in infants: comparison of clinical, radiological and ophthalmological data in corroborated cases. Child's Nerv Syst 26:637-645

2. Morris MW, Smith S, Cressman J (2000) Ancheta J Evaluation of infants with subdural hematoma who lack external evidence of abuse. Pediatrics 105:549-552

\footnotetext{
M. Vinchon

Department of Pediatric Neurosurgery, University hospital,

Lille, France

M. Vinchon $(\triangle)$

Pediatric Neurosurgery, Hôpital Roger Salengro,

Lille 59037 Cedex, France

e-mail: m-vinchon@chru-lille.fr
} 